\title{
Crocin Exhibits Antitumor Effects on Human Leukemia HL-60 Cells In Vitro and In Vivo
}

\author{
Yan Sun, ${ }^{1}$ Hui-Juan Xu, ${ }^{1}$ Yan-Xia Zhao, ${ }^{1}$ Ling-Zhen Wang, ${ }^{1}$ Li-Rong Sun, ${ }^{1}$ \\ Zhi Wang, ${ }^{2}$ and Xiu-Fang Sun ${ }^{3}$ \\ ${ }^{1}$ Department of Pediatric Hematology, The Affiliated Hospital of Medical College, Qingdao University, \\ No. 16 Jiangsu Road, Qingdao 266003, China \\ ${ }^{2}$ Department of Pharmacy, The Affiliated Hospital of Medical College, Qingdao University, Qingdao 266003, China \\ ${ }^{3}$ Department of Clinical Laboratory, The Affiliated Hospital of Medical College, Qingdao University, Qingdao, 266003, China
}

Correspondence should be addressed to Li-Rong Sun; xiufangsunqd@163.com

Received 25 December 2012; Revised 19 February 2013; Accepted 19 February 2013

Academic Editor: Mohamed Eddouks

Copyright (C) 2013 Yan Sun et al. This is an open access article distributed under the Creative Commons Attribution License, which permits unrestricted use, distribution, and reproduction in any medium, provided the original work is properly cited.

Crocin is a carotenoid of the saffron extract that exhibits antitumor activity against many human tumors. However, the effects of crocin on HL-60 cells in vivo have not been evaluated. This study aimed to examine the effects of crocin on HL-60 cells in vitro and in vivo and investigate the underlying mechanisms. HL-60 cells were treated by crocin, and cell proliferation, apoptosis, and cell cycle profiles were examined by MTT assay, AO/EB staining, and flow cytometry, respectively. Furthermore, HL-60 cells were xenografted into nude mice and treated by crocin, the tumor weight and size were calculated, and the expression of Bcl-2 and Bax in xenografts was detected by immunohistochemical staining. The results showed that crocin $(0.625-5 \mathrm{mg} / \mathrm{mL})$ inhibited HL-60 cell proliferation and induced apoptosis and cell cycle arrest at G0/G1 phase, in a concentration and time-dependent manner. In addition, crocin $(6.25,25 \mathrm{mg} / \mathrm{kg})$ inhibited the tumor weight and size of HL-60 xenografts in nude mice, inhibited Bcl-2 expression, and increased Bax expression in xenografts. In summary, crocin inhibits the proliferation and tumorigenicity of HL-60 cells, which may be mediated by the induction of apoptosis and cell cycle arrest and the regulation of Bcl-2 and Bax expression.

\section{Introduction}

Survival rates of children with acute lymphoblastic leukemia (ALL) and acute myeloid leukemia (AML) currently range from $83 \%$ to $94 \%$ and $60 \%$ to $65 \%$, respectively [1]. The survival rates have improved remarkably over the past decades, largely due to conventional chemotherapy. However, the side effects of cytotoxic chemotherapy remain significant. Further improvements in outcomes will depend on anticancer drugs with high efficacy and low toxicity.

Crocus sativus L., commonly known as saffron, is a perennial stemless herb of the large Iridaceae family and has been used in cancer therapy [2]. Crocin, a main water-soluble carotenoid of the saffron extract, exhibits anti-tumor activity against many human tumors, such as colorectal, pancreatic, and bladder cancer [3]. Notably, crocin significantly inhibits the growth of cancer cells but has no effects on normal cells
[4]. These studies provide strong evidence that crocin has high anti-tumor activity and low cytotoxicity.

It has been reported that carotenoids from saffron were effective in inhibiting the proliferation of HL-60 cells [5]. However, the effects of crocin on HL-60 cells in vivo have not been evaluated, and the mechanism responsible for the antileukemia effects of saffron remains elusive. In the present study, a series of experiments were performed to examine the effects of crocin on HL-60 cells in vitro and in vivo and investigate the underlying mechanisms.

\section{Materials and Methods}

2.1. Cell Line and Treatment. Human leukemia HL-60 cells were gifted from the Institute of Hematology and Blood Diseases Hospital, Chinese Academy of Medical Sciences, 


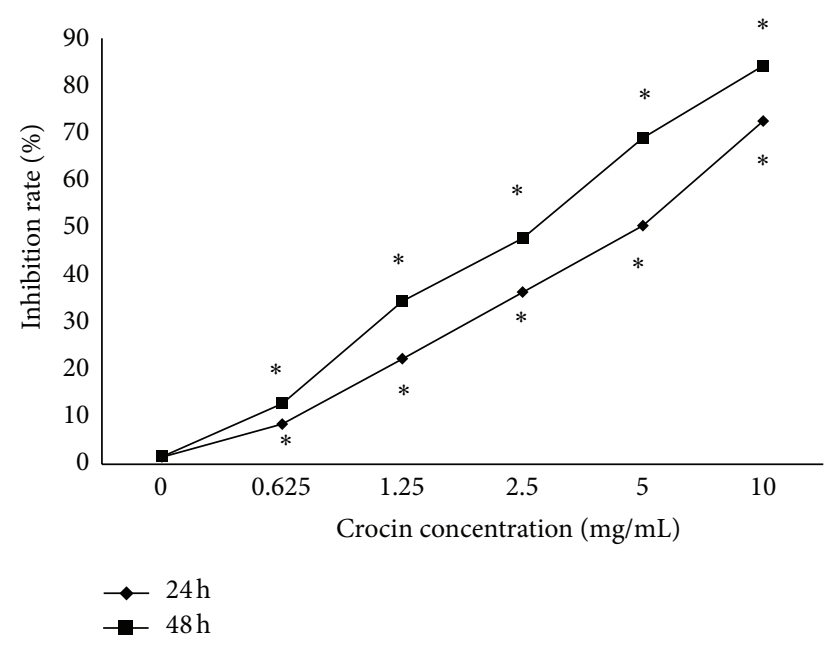

Figure 1: Crocin inhibits the proliferation of HL-60 cells in a doseand time-dependent manner. HL- 60 cells were treated by crocin at the indicated concentration for 24 or $48 \mathrm{~h}$, and the inhibition rate of proliferation was calculated based on MTT assay. ${ }^{*} P<0.05$ versus control.

Tianjin. HL-60 cells were cultured in RPMI-1640 medium (Gibco) supplemented with 10\% heat-inactivated fetal bovine serum (FBS) in a humidified incubator of $5 \% \mathrm{CO} 2$ at $37^{\circ} \mathrm{C}$. Crocin was purchased from Sigma (CAS Number 42553-651) and diluted in $10 \mathrm{mmol} / \mathrm{L}$ phosphate-buffered saline for the appropriate concentration upon used.

2.2. Cell Proliferation Assay. Cell proliferation was determined by using MTT assay. Briefly, HL-60 cells were treated with crocin $(0.625-10 \mathrm{mg} / \mathrm{mL})$ for $24 \mathrm{~h}$ or $48 \mathrm{~h}$. Then the cells were incubated with MTT solution ( $5 \mathrm{mg} / \mathrm{mL}$ in PBS, Sigma) for $4 \mathrm{~h}$ and solubilized with DMSO $(150 \mu \mathrm{L})$. The absorption was measured at $570 \mathrm{~nm}$ in an ELISA reader. The following formula was used for the calculation: cell inhibition rate (\%) $=[1-(A$ value of the experimental samples $/ A$ value of the control)] $\times 100 \%$.

2.3. AO/EB Staining. AO/EB staining of HL-60 cells was performed to detect the apoptotic and necrotic patterns as described previously [6]. Briefly, HL-60 cells $(2 \times$ $10^{5}$ cells $\left./ \mathrm{mL}\right)$ were treated by crocin $(0.625,1.25,2.5,5.0$, and $10 \mathrm{mg} / \mathrm{mL}$ ) for $24 \mathrm{~h}$ or $48 \mathrm{~h}$ and then washed three times with phosphate-buffered saline (PBS). The cells were stained with $100 \mu \mathrm{g} / \mathrm{mL}$ AO/EB for $5 \mathrm{~min}$. At least 200 cells were observed under a fluorescence microscope. The cells were classified as follows: viable, apoptotic, or necrotic. The percentage of apoptotic cell was then calculated by the formula: percentage of apoptotic cell $(\%)=($ amount of apoptotic cell/total cell examined) $\times 100 \%$.

2.4. Cell Cycle Analysis. HL-60 cells were treated with different concentrations of crocin. After $48 \mathrm{~h}$, cells were harvested and fixed in $70 \%$ ethanol at $4^{\circ} \mathrm{C}$ overnight. Fixed cells were stained with $5 \mu \mathrm{L}$ PI for 20 min on ice in the dark. Finally, the fluorescence emitted by PI-DNA complex was examined at
$488 \mathrm{~nm}$. The percentages of cells in various phases of the cell cycle, namely, G0, G1, S, and G2/M, were assessed using a flow cytometry and analyzed by Cell Quest software.

2.5. Animal Xenograft Model. A total of 32 males BALB/c nude mice (3 weeks old) were purchased from Shanghai Laboratory Animal Center, Chinese Academy of Sciences. Animals were maintained under standardized, sterilized conditions $\left(25 \pm 2^{\circ} \mathrm{C}, 60-70 \%\right.$ relative humidity, 12 hours dark/light cycle) in specific pathogen-free (SPF) laboratory, and were fed a regular nude mice chow. The mice were acclimatized to the housing condition for 1 week. All the experiments were conducted under the guidelines of laboratory animal use and care of the European Community (EEC Directive of 1986; 86/609/EEC).

Nude mice xenograft models were established by injecting HL-60 cells $\left(1 \times 10^{7} / 0.2 \mathrm{~mL}\right)$ subcutaneously on the back of the right shoulder of each mouse ( 4 weeks old). Immediately after the injection of HL- 60 cells, the nude mice were randomly divided into 4 groups $(n=8)$ : control group was treated with $0.2 \mathrm{~mL}$ saline/d by daily intraperitoneal injection (i.p. qd); 3 experimental groups were treated with $6.25,25$, and $100 \mathrm{mg} / \mathrm{kg}$ crocin (diluted in saline to $0.2 \mathrm{~mL}$, i.p. qd) for 28 days, respectively. Tumor formation time was recorded as the time from injecting HL-60 cells to forming tumor (diameter $5 \mathrm{~mm} * 5 \mathrm{~mm}$ ). Tumor formation rate was calculated as the numbers of mice forming tumor/the total numbers of each group $\times 100 \%$. The tumor volume and body weight were monitored daily throughout the experiments. Tumor volumes were measured by a digital caliper and calculated according to the following formula: tumor volume $\left(\mathrm{mm}^{3}\right)=0.4 \times L \times W^{2} ; L$ and $W$ were the major and minor dimensions of the tumor, respectively [7]. The change ratio of tumor volume was calculated using the formula: $\left(V_{n}-\right.$ $\left.V_{0}\right) / V_{0} \times 100 \% . V_{n}$ represented the tumor volume on the $n$th day after injecting HL-60 cells, and $V_{0}$ represented the initial tumor volume (diameter $5 \mathrm{~mm} * 5 \mathrm{~mm}$ ). The animals were sacrificed at the end of the experiment, and none of them died during the experiments.

2.6. Immunohistochemical Analysis. The immunohistochemical staining of $\mathrm{Bcl}-2$ and $\mathrm{Bax}$ in the tumor tissue was performed using the streptavidin-biotin-complex peroxidase kit (Boster, Wuhan, China). Finally, the slides were washed, dehydrated, and mounted for microscopic examination and enumeration immunoreactive cells (yellow to brown). Analysis of immunostaining in xenografts was done on a Media Cybernetics Image-Pro Plus analysis system linked to an Olympus microscope. The cells stained positive for Bcl-2 and Bax were quantified by counting the yellow to brown cells and the total number of cells at five randomly selected fields at 400x magnification.

2.7. Western Blot Analysis. The tumor tissues were collected and lysed in radioimmunoprecipitation assay (RIPA) buffer supplemented with protease inhibitors. The protein concentrations of the lysate were quantified using the bicinchoninic acid (BCA) protein assay kit (Beyotime Institute 


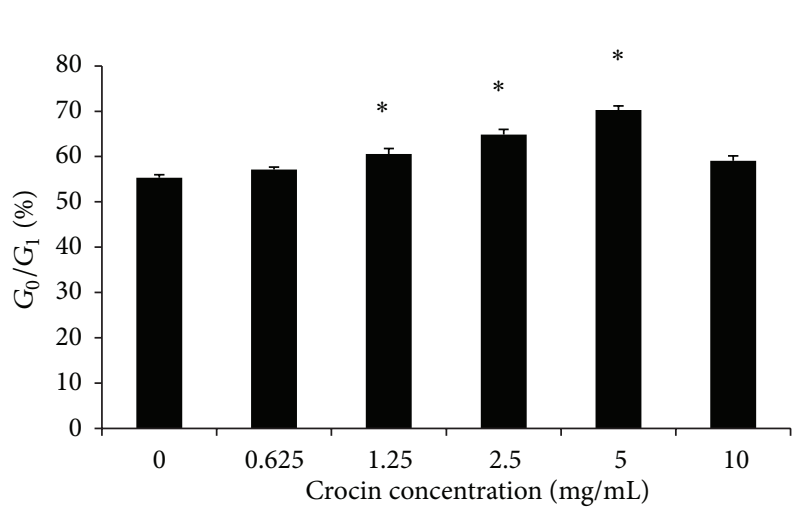

(a)

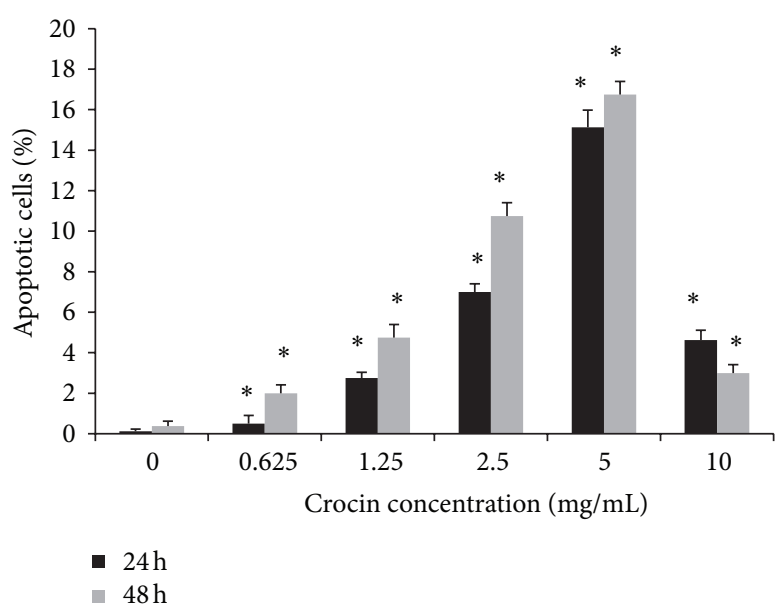

(b)

FIGURE 2: Crocin induces apoptosis and cell cycle arrest of HL-60 cells. (a) HL-60 cells were treated by crocin at the indicated concentration for $48 \mathrm{~h}$, and the ratio of cells at G0/G1 was calculated based on flow cytometry. (b) HL-60 cells were treated by crocin at the indicated concentration for 24 or $48 \mathrm{~h}$, and the percentages of apoptotic cells were calculated based on AO/EB staining. ${ }^{*} P<0.05$ versus control.

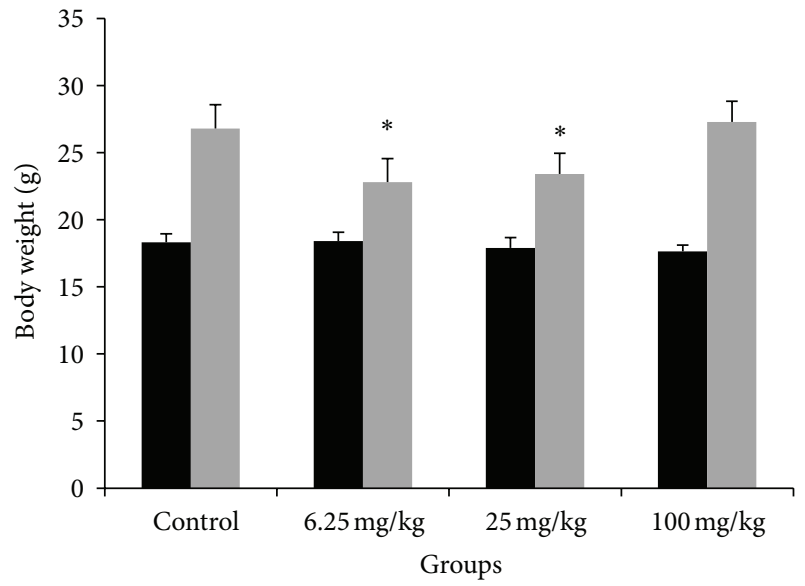

- When injected HL-60 cells

When executed

FIGURE 3: The body weight of mice that received HL-60 xenografts and crocin treatment. The body weight of mice was monitored daily throughout the experiment. Left panel: the body weight of mice at the beginning of receiving xenografts. Right panel: the body weight of mice after 28 days of crocin treatment. ${ }^{*} P<0.01$ versus control.

of Biotechnology, China). Equal amounts of protein were separated by $10 \%$ sodium dodecyl sulfate-polyacrylamide gel electrophoresis (SDS-PAGE) and transferred to polyvinylidene fluoride (PVDF) membranes (Bio-Rad, Hercules, CA, USA). Membranes were blocked with PBST (PBS with 0.05\% Tween-20) containing 5\% nonfat dry milk for $1 \mathrm{~h}$ and then incubated at $4^{\circ} \mathrm{C}$ overnight with Bcl-2, Bax, or $\beta$-actin antibody (Sigma) in fresh blocking buffer. Membranes were then washed with PBST, incubated with horseradish peroxidaseconjugated secondary antibody (Santa Cruz Biotechnology, Santa Cruz, CA, USA) for $1 \mathrm{~h}$, and developed with the ECL western blotting system. Protein levels were normalized to $\beta$ actin.

2.8. Statistical Analysis. Data were presented as the mean \pm standard deviation (SD) and analyzed by one-way analysis of variance (ANOVA) followed by LSD test using the SPSS 17.0 software. Statistical significance of tumor formation rate was assessed with Fisher's exact probability test. Significant differences were defined as $P<0.05$.

\section{Results}

3.1. Crocin Inhibits the Proliferation of HL-60 Cells. MTT assay showed that compared with the control group, crocin at the various concentrations $(0.625-10 \mathrm{mg} / \mathrm{mL})$ significantly inhibited HL-60 cell proliferation, and the inhibitory effect of crocin on HL-60 cell proliferation was dose and time dependent (Figure 1).

3.2. Crocin Induces Apoptosis and Cell Cycle Arrest of HL-60 Cells. To determine whether crocin inhibits the proliferation of HL-60 cells through the regulation of cell cycle progression and apoptosis, first we performed flow cytometry using PI staining. We observed a significant increase of G0/G1 cells from $55.33 \%$ in control group to $70.27 \%$ in the crocin-treated group $(5.0 \mathrm{mg} / \mathrm{mL})$. However, at $10 \mathrm{mg} / \mathrm{mL}$, crocin could not further increase the cell ratio in G0/G1 phase (Figure 2(a)). These results suggest that crocin was capable of inducing cell cycle arrest at G0/G1.

$\mathrm{AO} / \mathrm{EB}$ staining showed that uniformly green live cells with normal morphology were seen in the control HL60 cells, whereas green early apoptotic cells with nuclear margination and chromatin condensation occurred in HL60 cells treated by $0.625-2.5 \mathrm{mg} / \mathrm{mL}$ crocin, and orange later apoptotic cells with fragmented chromatin and apoptotic bodies were seen in HL-60 cells treated by $5 \mathrm{mg} / \mathrm{mL}$. The 


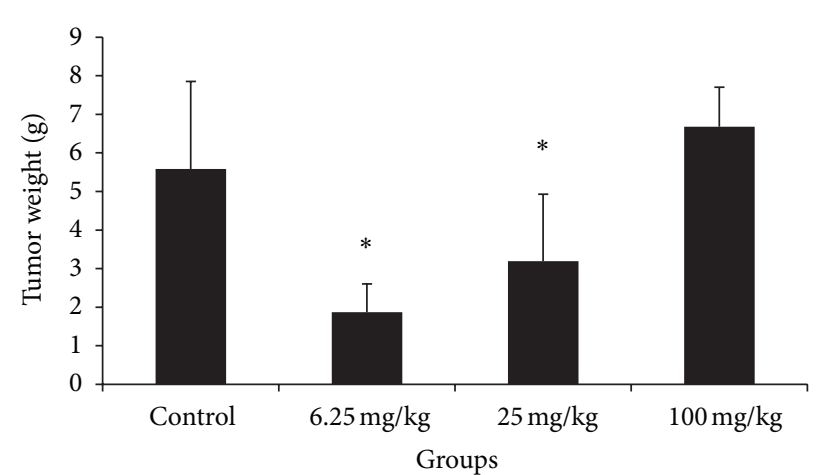

(a)

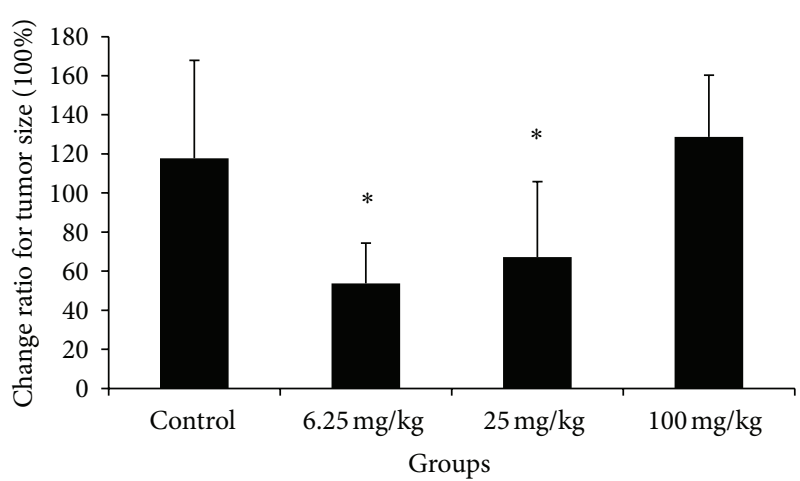

(b)

FIGURE 4: The tumor weight and size in mice that received HL-60 xenografts and crocin treatment. After 28 days of treatment, the mice were sacrificed, and the xenografts were excised. (a) Tumor weight in different treatment groups. (b) The change ratio of tumor size in different treatment groups. ${ }^{*} P<0.01$ versus control.

percentage of apoptotic cell significantly increased gradually with crocin concentration increased from 0.625 to $5 \mathrm{mg} / \mathrm{mL}$, compared with the control group, and the effects were time dependent (Figure 2(b)). However, at the concentration of $10 \mathrm{mg} / \mathrm{mL}$, crocin induced cell necrosis rather than apoptosis. These results suggest that crocin could induce HL-60 cell apoptosis.

3.3. Antitumor Efficacy of Crocin In Vivo. After being injected HL-60 cells, spontaneous activity and food intake of all mice decreased. At the time of receiving HL-60 cells, there was no significant difference in the body weight between the four groups. As the tumors grew, all the mice's weight increased (Figure 3). There was no treatment-related death of mice.

The tumor formation rate of the control and experiment groups $(6.25,25,100 \mathrm{mg} / \mathrm{kg}$ crocin) was $100 \%, 50 \%, 75 \%$, and $75 \%$, respectively. There was no significant difference in the tumor formation rate among the four groups. The tumor formation time of the control and the experiment groups was $11.50 \pm 1.60,20.00 \pm 1.15,14.30 \pm 1.86$, and $10.50 \pm 1.64 \mathrm{~d}$, respectively. The tumor formation time of the experiment group $(6.25 \mathrm{mg} / \mathrm{kg})$ was obviously longer than the other three groups, and the tumor formation time of the experiment group $(25 \mathrm{mg} / \mathrm{kg})$ was longer than the control and experiment groups $(100 \mathrm{mg} / \mathrm{kg})$. These results suggest that crocin at the dose of 6.25 and $25 \mathrm{mg} / \mathrm{kg}$ could slow the formation of HL60 cell xenograft in nude mice.

At the end of the study, the xenografts were excised from each sacrificed mouse, and tumor weight and volume were calculated. Tumor weight and the change ratio of tumor size in mice treated by crocin at the doses of 6.25 and $25 \mathrm{mg} / \mathrm{kg}$ were both significantly inhibited compared with the control group (Figures 4(a) and 4(b)). These results suggest that crocin could inhibit the growth of HL-60 cell xenograft in nude mice.

To investigate whether the regression of tumor growth by crocin is due to the induction of apoptosis in vivo, we performed immunohistochemistry analysis of Bcl-2 and Bax expression in xenograft. The number of Bcl-2 positive cells was decreased in tumors from mice treated by 6.25 or $25 \mathrm{mg} / \mathrm{kg}$ crocin, compared to those from controls. In contrast, the number of Bax positive cells was increased in tumors from mice treated by 6.25 or $25 \mathrm{mg} / \mathrm{kg}$ crocin, compared to those from controls (Figure 5).

We also performed western blot analysis of $\mathrm{Bcl}-2$ and $\mathrm{Bax}$ expression in xenografts. The results showed that the protein level of $\mathrm{Bcl}-2$ was reduced in tumors derived from mice treated with 6.25 or $25 \mathrm{mg} / \mathrm{kg}$ crocin, compared to those from control. In contrast, the protein level of Bax was increased in tumors derived from mice treated with 6.25 or $25 \mathrm{mg} / \mathrm{kg}$ crocin, compared to those from control (Figure 6). Taken together, these data indicate that crocin could reduce $\mathrm{Bcl}-2$ expression and increase Bax expression, leading to increased apoptosis in HL-60 cell xenograft.

\section{Discussion}

In the present study, we showed that crocin, a main compound derived from Crocus sativus extract, could inhibit the proliferation and induce the apoptosis of HL-60 cells both in vitro and in vivo. These data provide strong evidence that crocin has the potential for the treatment of leukemia.

Anti-tumor drugs are known to regulate cell cycle progression, inhibit cell growth and proliferation, and induce apoptosis in tumor cells [8]. Crocin could induce the significant alteration of gene expression profile of T24 cell, and its anti-tumor effects have been proposed to be medicated at least in part by regulating the cell cycle progression [5]. Another study reported that crocin could induce apoptosis and G1-phase cell cycle arrest of human pancreatic cancer cell line [4]. In this study we showed that within the range of $0.625-5 \mathrm{mg} / \mathrm{mL}$, crocin induced the apoptosis of HL-60 cells in a dose-dependent manner. However, higher dose of crocin at $10 \mathrm{mg} / \mathrm{mL}$ induced cell necrosis, suggesting the toxic effect of crocin at high dose. Similarly, we found that crocin at the dose of $0.625-5 \mathrm{mg} / \mathrm{mL}$ could induce G0/G1 phase arrest of HL-60 cells in a dose dependent manner. Collectively, these 


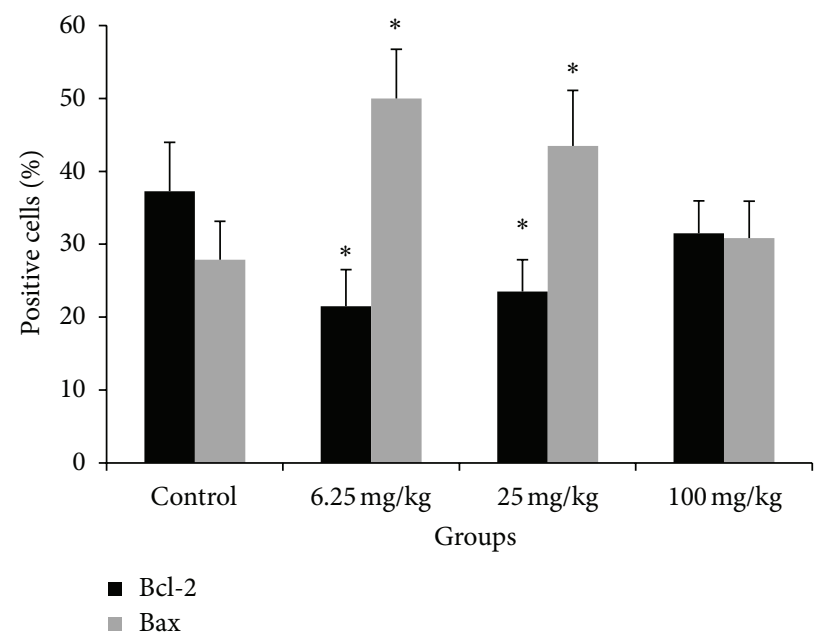

(a)

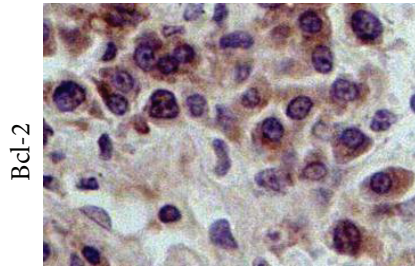

Control

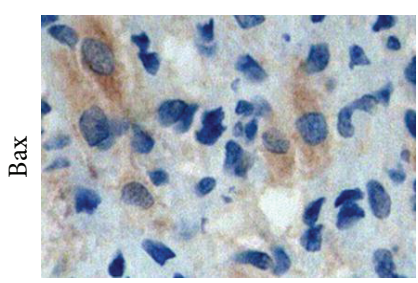

Control

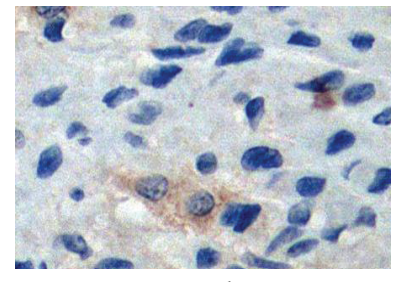

$6.25 \mathrm{mg} / \mathrm{kg}$

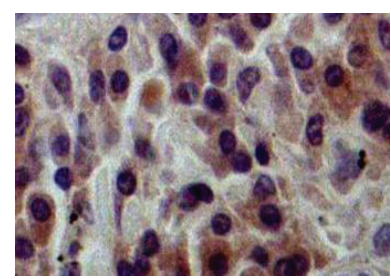

$6.25 \mathrm{mg} / \mathrm{kg}$

(b)

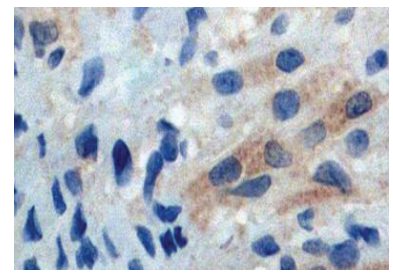

$25 \mathrm{mg} / \mathrm{kg}$

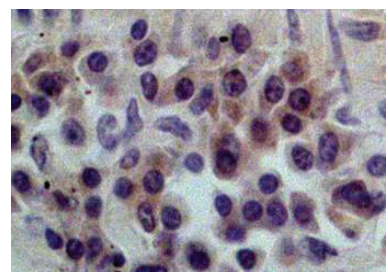

$25 \mathrm{mg} / \mathrm{kg}$

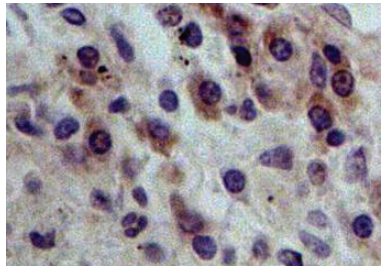

$100 \mathrm{mg} / \mathrm{kg}$

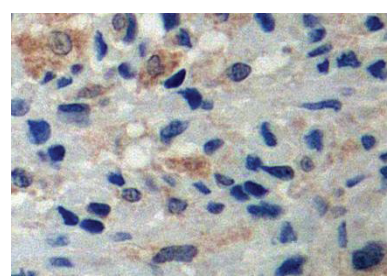

$100 \mathrm{mg} / \mathrm{kg}$

(c)

FIGURE 5: Immunohistochemical staining of Bcl-2 and Bax expression in HL-60 xenografts. (a) The percentages of cells stained positively for Bcl-2 and Bax in different groups. (b) Immunohistochemical staining of Bcl-2 in HL-60 xenografts from different groups. (c) Immunohistochemical staining of Bax in HL-60 xenografts from different groups. Magnification: 400x.

data suggest that crocin inhibits HL-60 cell proliferation by inducing G0/G1 arrest and apoptosis of HL-60 cells.

To confirm our in vitro results, we employed nude mice xenograft model to evaluate the in vivo anti-tumor effects of crocin. Our results showed that crocin at the dose of 6.25 , $25 \mathrm{mg} / \mathrm{kg}$ had strong inhibitory effect on HL-60 cell growth in nude mice, while the high dose $(100 \mathrm{mg} / \mathrm{kg})$ had no significant inhibitory effect, perhaps due to the toxic effects.

There was no accidental death throughout the course of the animal experiment, indicating the safety of crocin. It was demonstrated that orally administered crocin was not absorbed in plasma either after a single dose or repeated doses, and crocin was excreted largely through the intestinal tract following oral administration [9]. Another study reported that crocin was not detected in blood plasma following oral administration [10]. In the present study, oral administration was not adopted, and we observed obvious anti-tumor effects of crocin after daily intraperitoneal injection in nude mice, indicating that crocin could be absorbed following intraperitoneal injection.

Medicinal herbs have been shown to exert anti-tumor effects by the induction of apoptosis in cancer cells including leukemia cells [11-13]. Bcl-2 and Bax are important antiapoptotic and proapoptotic molecules, respectively. Crocin suppressed TNF- $\alpha$ induced apoptosis of PC12 cells by modulating mRNA expression of $\mathrm{Bcl}-2$ family proteins [14]. In this study, immunohistochemical and western blot analysis indicated that crocin at dose of 6.25 or $25 \mathrm{mg} / \mathrm{kg}$ could increase Bax expression while decreasing Bcl-2 expression. These results suggest that crocin inhibits tumor growth by modulating the expression of apoptosis-related molecules. However, further investigation is necessary to elucidate the 


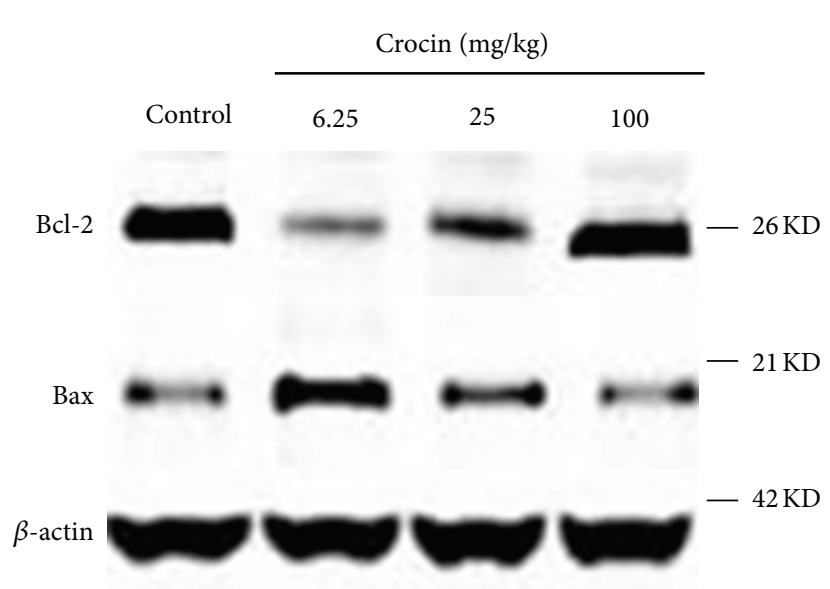

(a)

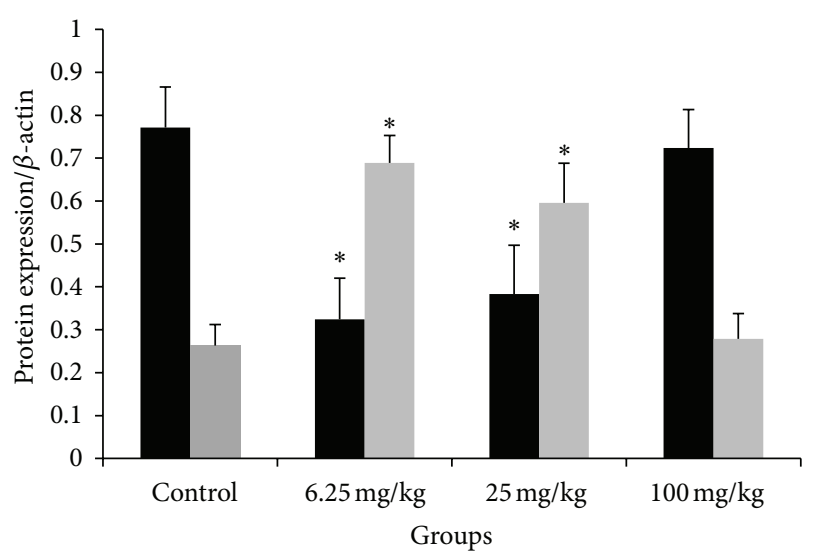

- Bcl-2

Bax

(b)

FIGURE 6: Crocin regulates the expression levels of Bcl-2 and Bax in HL-60 xenografts. The mice were treated with crocin (0, 6.25, 25, or $100 \mathrm{mg} / \mathrm{kg}, \mathrm{qd}$ ), and xenografts were collected for western blot analysis. Left panel: representative blots. Right panel: quantization of relative $\mathrm{Bcl}-2$ and Bax protein levels in different groups. $\beta$-actin was used as loading control. ${ }^{*} P<0.05$ versus control.

molecular mechanism by which crocin regulates the expression of Bcl-2 and Bax.

\section{Conclusions}

In summary, both in vitro and in vivo studies demonstrate that crocin inhibits the proliferation and tumorigenicity of HL-60 cells, which may be mediated by the induction of apoptosis and cell cycle arrest and the regulation of Bcl-2 and Bax expression. These findings suggest that crocin has the potential to be developed as a new drug with high efficacy and low toxicity for the treatment of leukemia.

\section{Conflict of Interests}

The authors declare that they have no conflict of interests.

\section{References}

[1] M. C. Ethier, E. Blanco, T. Lehrnbecher et al., "Lack of clarity in the definition of treatment-related mortality: pediatric acute leukemia and adult acute promyelocytic leukemia as examples," Blood, vol. 118, no. 19, pp. 5080-5083, 2011.

[2] F. I. Abdullaev and J. J. Espinosa-Aguirre, "Biomedical properties of saffron and its potential use in cancer therapy and chemoprevention trials," Cancer Detection and Prevention, vol. 28, no. 6, pp. 426-432, 2004.

[3] H. Bakshi, S. Sam, R. Rozati et al., "DNA fragmentation and cell cycle arrest: a hallmark of apoptosis induced by crocin from Kashmiri Saffron in a human pancreatic cancer cell line," Asian Pacific Journal of Cancer Prevention, vol. 11, no. 3, pp. 675-679, 2010.

[4] H. H. Aung, C. Z. Wang, M. Ni et al., "Crocin from Crocus sativus possesses significant anti-proliferation effects on human colorectal cancer cells," Experimental Oncology, vol. 29, no. 3, pp. 175-180, 2007.
[5] P. A. Tarantilis, H. Morjani, M. Polissiou, and M. Manfait, "Inhibition of growth and induction of differentiation of promyelocytic leukemia (HL-60) by carotenoids from Crocus sativus L."” Anticancer Research A, vol. 14, no. 5, pp. 1913-1918, 1994.

[6] B. C. Cavalcanti, D. P. Bezerra, H. I. Magalhaes et al., "Kauren19-oic acid induces DNA damage followed by apoptosis in human leukemia cells," Journal of Applied Toxicology, vol. 29, no. 7, pp. 560-568, 2009.

[7] K. H. Lu, Y. F. Chang, P. H. Yin et al., "In vitro and in vivo apoptosis-inducing antileukemic effects of Mucuna macrocarpa stem extract on HL-60 human leukemia cells," Integrative Cancer Therapies, vol. 9, no. 3, pp. 298-308, 2010.

[8] Y. C. Hseu, S. C. Chen, H. C. Chen, J. W. Liao, and H. L. Yang, "Antrodia camphorata inhibits proliferation of human breast cancer cells in vitro and in vivo," Food and Chemical Toxicology, vol. 46, no. 8, pp. 2680-2688, 2008.

[9] L. Xi, Z. Qian, P. Du, and J. Fu, "Pharmacokinetic properties of crocin (crocetin digentiobiose ester) following oral administration in rats," Phytomedicine, vol. 14, no. 9, pp. 633-636, 2007.

[10] A. Asai, T. Nakano, M. Takahashi, and A. Nagao, "Orally administered crocetin and crocins are absorbed into blood plasma as crocetin and its glucuronide conjugates in mice," Journal of Agricultural and Food Chemistry, vol. 53, no. 18, pp. 7302-7306, 2005.

[11] H. Zhang, J. Y. Yang, F. Zhou et al., "Seed oil of Brucea javanica induces apoptotic death of acute myeloid leukemia cells via both the death receptors and the mitochondrial-related pathways," Evidence-based Complementary and Alternative Medicine, vol. 2011, Article ID 965016, 2011.

[12] H. J. Lin, C. P. Tseng, C. F. Lin et al., "A Chinese herbal decoction, modified Yi Guan Jian, induces apoptosis in hepatic stellate cells through an ROS-mediated mitochondrial/caspase pathway," Evidence-based Complementary and Alternative Medicine, vol. 2011, Article ID 459531, 2011.

[13] D. H. Lee, K. I. Park, H. S. Park et al., "Flavonoids isolated from Korea Citrus aurantium L. Induce G2/M phase arrest and apoptosis in human gastric cancer AGS cells," Evidence-Based 
Complementary and Alternative Medicine, vol. 2012, Article ID 515901, 11 pages, 2012.

[14] S. Soeda, T. Ochiai, L. Paopong, H. Tanaka, Y. Shoyama, and H. Shimeno, "Crocin suppresses tumor necrosis factor-alphainduced cell death of neuronally differentiated PC-12 cells," Life Sciences, vol. 69, no. 24, pp. 2887-2898, 2001. 


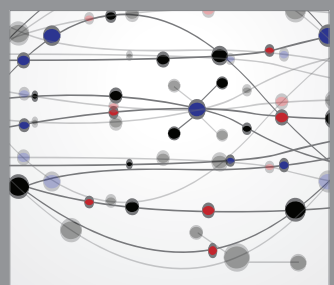

The Scientific World Journal
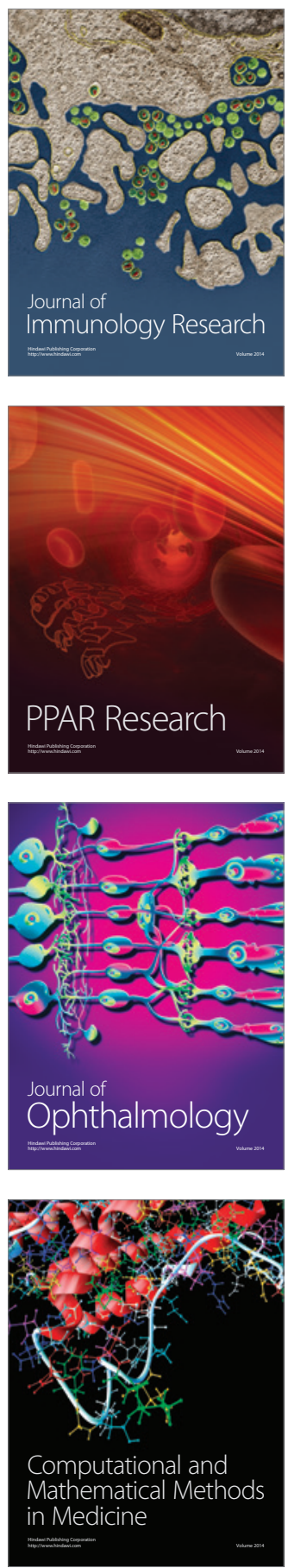

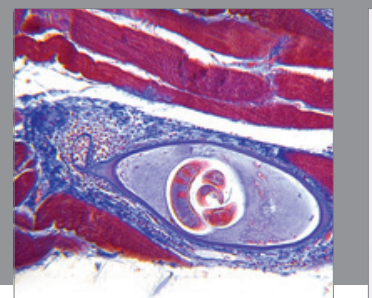

Gastroenterology

Research and Practice
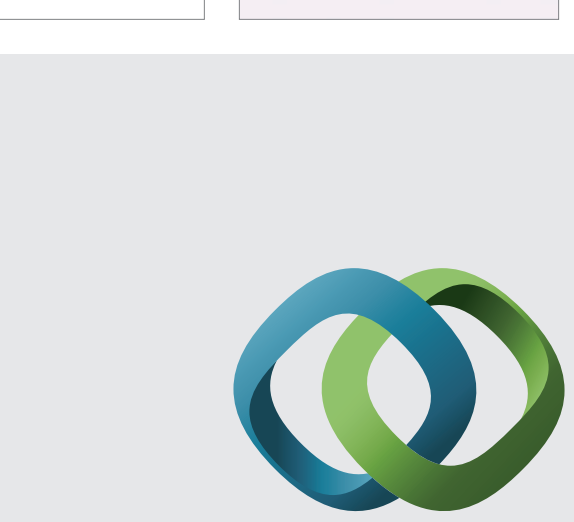

\section{Hindawi}

Submit your manuscripts at

http://www.hindawi.com
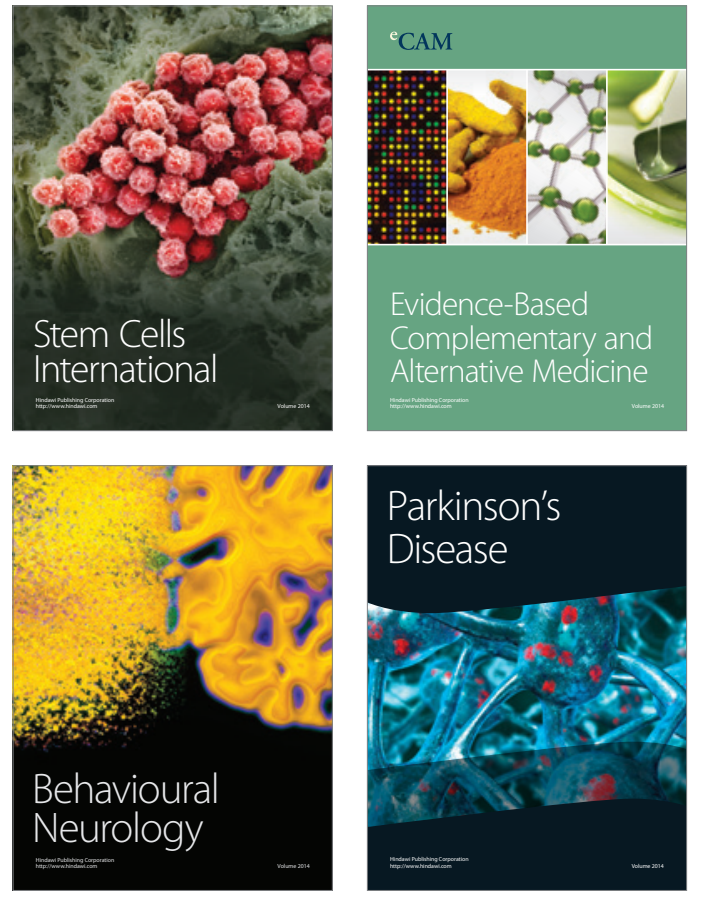
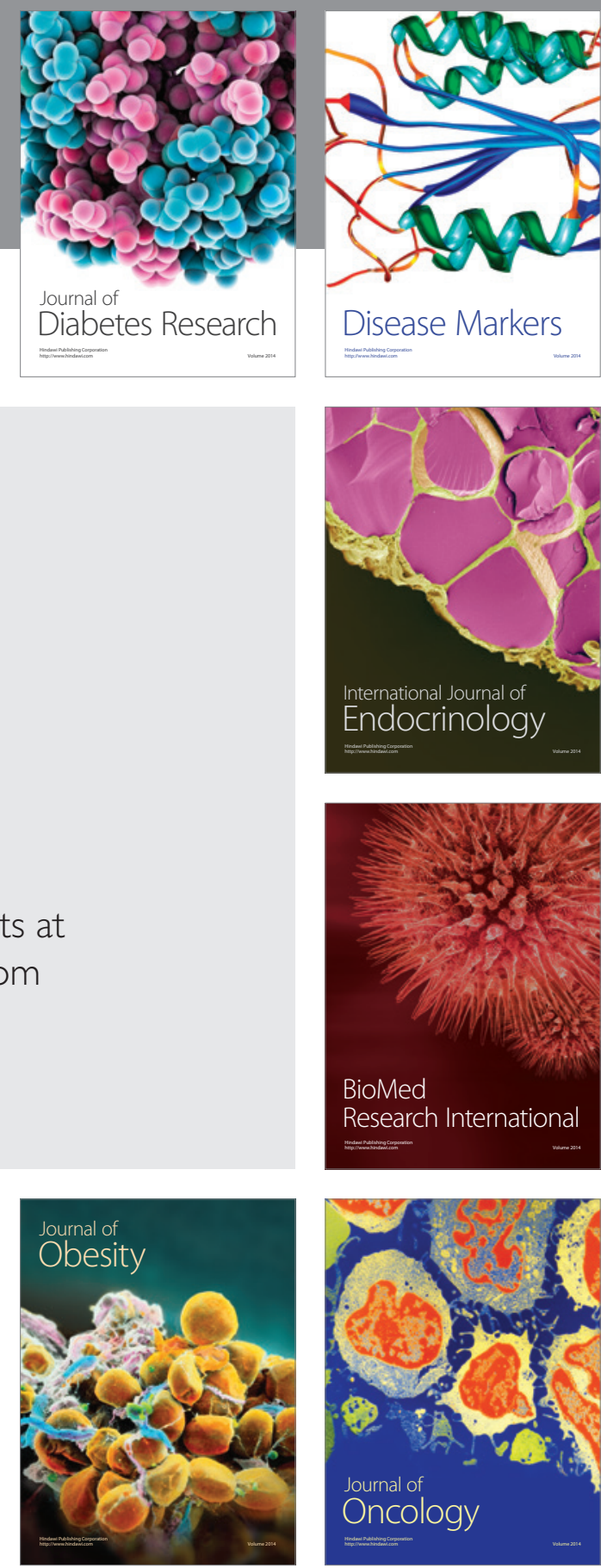

Disease Markers
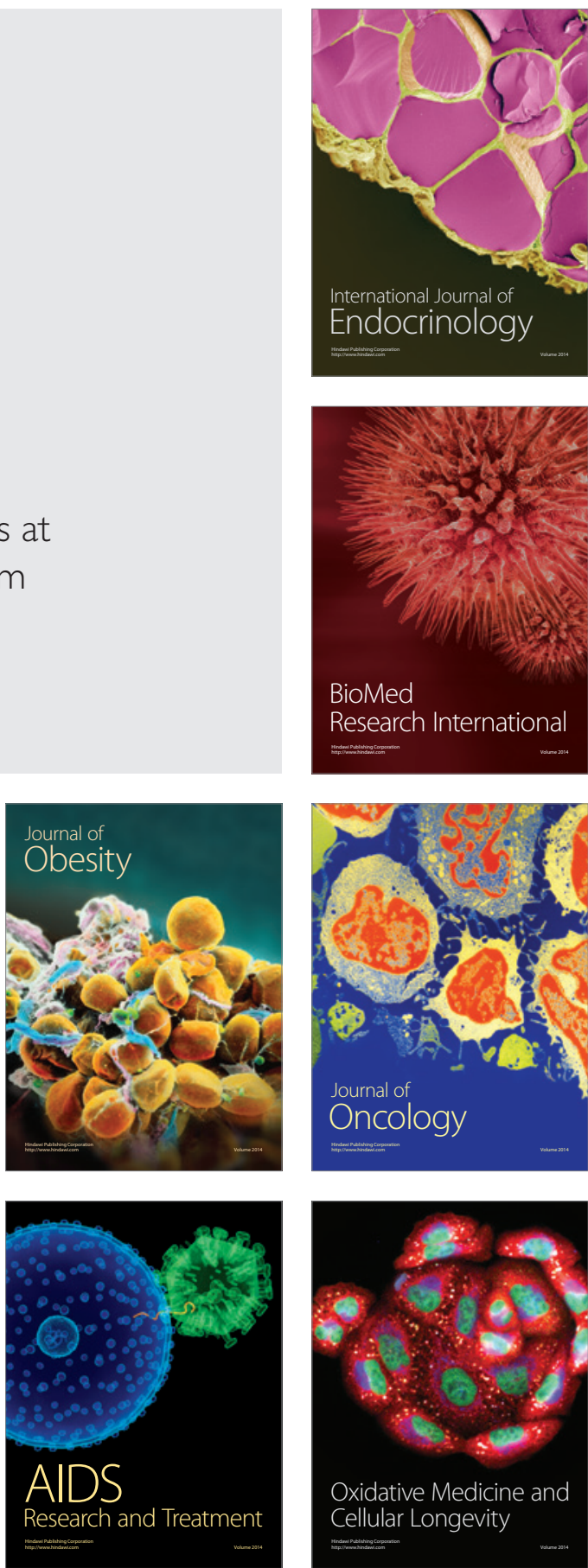